\title{
Attitudes towards the Effects of Covid-19 on the Environment
}

\author{
José Marcos Bustos-Aguayo ${ }^{1}$, Javier Carreón-Guillén ${ }^{1}$, Margarita Juárez-Nájera ${ }^{2}$, Jorge Hernández-Valdés ${ }^{1}$, Cruz García-Lirios ${ }^{3 *}$ \\ ${ }^{1}$ Universidad Nacional Autónoma de México \\ ${ }^{2}$ Universidad Autónoma metropolitana \\ ${ }^{3}$ Universidad Autónoma del Estado de México
}

*Corresponding author: Cruz García-Lirios, Universidad Autónoma del Estado de México

Received Date :June 06, 2020; Accepted Date: July 05, 2020; Published Date: July 09, 2020.

Citation: Bustos-Aguayo J M, Javier C Guillén, Margarita J Nájera, Jorge H Valdés, Cruz G Lirios, (2020) Attitudes towards the Effects of Covid-

19 on the Environment. J Clinical Case Reports and Studies, 1(3): Doi:10.31579/2690-8808/014

Copyright: () 2020. Cruz García-Lirios. This is an open-access article distributed under the terms of the Creative Commons Attribution License,

which permits unrestricted use, distribution, and reproduction in any medium, provided the original author and source are credited.

\begin{abstract}
The objective of the present work was to specify a model for the study of attitudes towards the effects of the pandemic on the environment. An exploratory, cross-sectional and correlational work was carried out with 100 students, considering their confinement and intensive use of electronic technologies, devices and networks. A factorial structure was found that explained $35 \%$ of the total variance, although the research design limited the results to the study setting, suggesting the extension of the work towards the contrast of the proposed model.
\end{abstract}

Keywords: Information; theory; model; attitude; behavior

\section{Introduction}

As of this writing, the SARS-COV-2 coronavirus pandemic and COVID19 disease have infected 10 million people, sickened 5 million and killed half a million. In Mexico, 200,000 have been infected, 50,000 have become ill and 25,000 have died. The health crisis has forced confinement and gradually led to a recession and economic crisis shaped by unemployment and inflation.

Faced with this bleak picture, people have developed attitudes or dispositions against and in favor of the situation, the government, their jobs, their families and themselves in the face of the health and economic crisis, highlighting the emotions of anxiety, anger or fear, although also dispositions emerge to carry out actions that mitigate the effects of the pandemic, as well as strategies for entrepreneurship and solidarity and fraternal collaboration with others.

Precisely, the objective of this work is to specify a model for the study of attitudes towards the pandemic, the rulers and the ruled, considering the effects of the health and economic crisis during a prolonged confinement that has lasted four months and another two are expected. Months more with the expectation of a new outbreak of infections, diseases and deaths.

The contributions of this work to the state of the question are: 1) review of the conceptual theoretical framework, 2) methodological approach to the problem, 3) diagnosis of the phenomenon, 4) discussion of the findings, 5) reflection of contributions and implications.

Thus, in the first section the theoretical and conceptual corpus that explain the appearance of attitudes towards risk events such as pandemics are exposed. Thus, in the following section the most recent and specialized findings are reviewed in order to be able to notice the research agenda. Next, the decisions that led to the study of the problem are presented to offer a diagnosis of the frequencies, validity and reliability of the responses to the instrument that measures the question. In addition, the scope and limits of work are discussed in a penultimate section in order to offer a global reflection in the last section.

\section{Theory of attitudes towards health}

in this section, we review the theoretical and conceptual frameworks that include attitudes in explanatory and predictive models of behavior in specific situations, such as reasoned action and planned behavior.

Both theories, in the context of the confinement of people, the health crisis and the economic recession, anticipate scenarios of scarcity, shortages, unhealthiness and famine (Amemiya, 2020). These are predictive models of deliberate, planned and systematic behavior of individuals in favor of mitigation policies, use of masks, constant hand washing, application of tests, investment in treatments and vaccines.

In the 1970s a prolific context of explanatory corpus emerged, including the Theory of Reasoned Action. It was an approach that modeled attitudes as mediators of the effect of beliefs and values on human behavior (Anguiano, 2020). In the health field, reasoned action demonstrated a predictive power of self-care and adherence to treatment by anticipating risky situations and behaviors. It was the first conceptual framework dedicated to the study of relationships between health professionals and users of public health services.

The explanatory structure of the reasoned action consisted of associating the surrounding information about a disease with respect to the prevention strategies, the intentions to carry out a treatment and the adherence to that process (Garcia, 2020). However, very soon the studies revealed a low correlation between this surrounding information regarding the follow-up and execution of health recommendations.

Consequently, in the 1990s, a new proposal underlies those beliefs about the surrounding information in the media regarding the implementation of these recommendations (Hernández, 2020). The Theory of Planned 
Behavior, unlike reasoned action, raises a variable related to the control that people assume in the face of a disease. $e$ is about perceived behavioral control which specifies people's beliefs and norms.

In other words, in the face of a widespread disease such as an epidemic or pandemic, a perception of control develops that regulates what the person believes in the information they receive (Molina, 2020). Such is the difference between reasoned action and planned behavior that the explanatory and predictive power is considerable.

It is possible to appreciate that attitudes are mediators of both processes, reasoning action and planned behavior, but in a confinement scenario, they regulate more information in planned behavior and therefore, selfcare and adherence to treatment can be anticipated (Bustos, 2020).

In synthesis, both models, reasoned action and planned behavior, have turned out to be useful for the explanation and prediction of the prevention of a disease or adherence to its treatment. Both theories include attitudes as mediators or regulators of information beliefs and perceptions.

\section{Attitude studies towards contingencies}

this section presents the most recent studies on attitudes as mediators of beliefs and perceptions in their deliberate and planned process of incidence on intentions and behaviors. These investigations, in the context of the confinement of people, have anticipated the differences between those who are in favor of confinement policies and the spread of the infected, sick and dead versus those who avoid these contents or develop questions to their authorities.

Traditionally, attitudinal studies have focused on three dimensions related to feelings towards media information, the representation of data or images, as well as the intentions to carry out or not the recommendations of authorities (Limón, 2020). In the deliberate action process, attitudes are provisions against or in favor of mitigation policies, but it is in planned behavior that these provisions filter perceptions of control, delimiting information that will influence decision-making and execution of the action.

In this way, the three components of attitudes are information filters for more efficient, effective and effective decision making and execution (Pérez, 2020). Therefore, the modeling of attitudes in predicting behavior is preferably done from the cognitive rational component. It is a minuscule process where the information is processed in such a way that it will end up segmented into data, phrases or images that determine decisions and actions, both reasoned and planned.

In the case of the intentional component, the probability of carrying out an action will depend on the calculation of possibilities that the person performs when processing data, images or phrases (Rivera, 2020). Therefore, communication of risks around the pandemic is of vital importance.

In synthesis, the components; affective, cognitive and intentional attitudes filter data, images and phrases in order to define a decision and consequent action.

\section{Modeling attitudes towards the effects of COVID-19 on the environment}

In this space, the three components of attitudes are modeled, considering the beliefs and perceptions of the information disseminated in the media and their impact on prevention actions; confinement, use of masks, hand washing, diagnostic tests and healthy distance.

Based on the theoretical, conceptual and empirical frameworks reviewed, it is possible to model the explanatory variables of the media impact of the pandemic on the preventive behavior of people. It is a media phenomenon in that it is through television, radio, the press or networks that information on people, sick and dead from the COVID-19 disease is disseminated.

In the assumption that the government intends to mitigate the effects of the pandemic, reducing the number of risks, infections, sick and dead, the declaration of health contingency and the political communication strategy of risk control and management (Quiroz, 2020). Attitudes can emerge as predominant by filtering what the person believes or perceives about the pandemic.

In this scenario, cognitive attitudes are the most relevant because they process data, images and phrases of authorities in the face of the pandemic, although intentional and affective attitudes also stand out for receiving messages (Sandoval, 2020). The affective component activates negative and positive emotions and feelings towards the authorities, biasing their evaluation in the management of the health crisis.

However, by disseminating pandemic mitigation data, motivational phrases, or images of technological, organized, or scientific response, authorities reduce or increase those emotions of anger, anxiety, or fear. In this process, cognitive attitudes change a negative disposition into positive, or from positive to negative depending on the type of government message (Carreon, 2020).

In the case of intentions as a dimension of attitudes, they are determined by the filter of cognition. This is the case of people who declare not to believe in the pandemic but die from that neglect. This news or experience translates into a new provision that incorporates the high risk of contagion or death, causing preventive self-care.

In summary, the three components can be associated to process data, phrases or images in order to guide decisions and actions.

Now, in the case of attitudes towards the effects of COVID-19 on the environment, it is necessary to consider that the media have disseminated images and data on the decrease in air pollution, the visit of animals to cities, the purification of beaches or rivers, but also the increase in sanitary waste; masks, syringes, gowns, towels and sheets.

In these events, the three dimensions of attitudes; Emotional, cognitive and intentional can explain mobility, the consumption of products, and the use of energy or water in the face of confinement. In this sense, the combination of the dimensions of attitudes with the objects of affect, cognition and intention results in an inventory that the present work used to observe their distribution.

\section{Method}

Design. An exploratory, cross-sectional and correlational work was carried out with a sample of 100 students $(\mathrm{M}=24.31 \mathrm{SD}=3.21 ; \mathrm{M}=$ $9^{\prime} 975.32 \mathrm{SD}=743.23$ monthly income) from a public university in central Mexico , considering prolonged confinement, as well as the intensive use of electronic technologies, devices and networks.

Instrument. The Attitudes Scale towards the Pandemic EAP-21) was built, which includes 21 assertions around three preponderant dimensions; emotional-affective-sentimental ("The coronavirus affects consumers "), cognitive ("The pandemic is an effect of climate change") and intentional-behavioral ("Ecologists work more in this confinement"). All items are answered with one of five options ranging from $0=$ "not at all likely" to $5=$ "quite likely".

Procedure. The invitations were sent to the institutional emails of the respondents. Once the acknowledgments were received, the informed consent was sent, highlighting the non-payment for responding to the questionnaire, as well as the guarantee of confidentiality and anonymity both in the coding and in the interpretation of the responses.

Analysis. The data were processed in the statistical analysis package for social sciences version 23.0 considering the requirements of normal 
distribution, reliability, adequacy, sphericity, validity, linearity, normality and independence for the structures of trajectories and relationships between the variables in order to to test the null hypothesis of significant differences between the structures reported in the literature with respect to the observations made in this work.

\section{Results}

Table 1 shows the values of normality, reliability and validity among the variables that reflect the responses to the items that measure attitudes towards the pandemic, confinement and government action as a civilian in the face of health and economic crises.

\begin{tabular}{|c|c|c|c|c|c|c|c|}
\hline نْ & 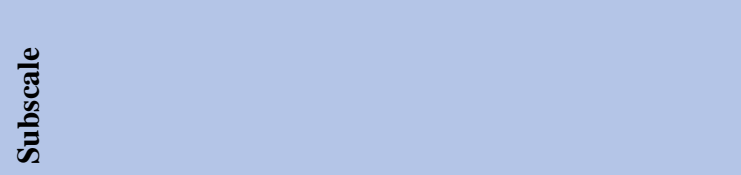 & $\stackrel{\varpi}{\Xi ँ}^{\Xi}$ & 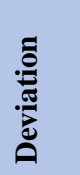 & $\frac{\pi}{\frac{\pi}{2}}$ & 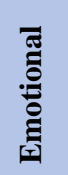 & : & 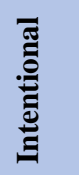 \\
\hline & Emotional & & & 781 & & & \\
\hline $\mathrm{r} 1$ & Coronavirus affects consumerists & 4.32 & 1.34 & 762 & 365 & & \\
\hline $\mathrm{r} 2$ & The pandemic subtracts people's environmentalism & 4.15 & 1.81 & 703 & 397 & & \\
\hline r3 & Confinement is a solution to contamination & 4.67 & 1.09 & 771 & 380 & & \\
\hline $\mathrm{r} 4$ & The use of masks is for environmentalists & 4.83 & 1.78 & 751 & 365 & & \\
\hline r5 & Asymptomatic also pollute & 4.05 & 1.56 & 743 & 387 & & \\
\hline r6 & Infected also contaminate & 4.32 & 1.34 & 702 & 370 & & \\
\hline r7 & Quarantine is resigned to mobility & 4.34 & 1.21 & 713 & 365 & & \\
\hline & Cognitive & & & 798 & & & \\
\hline r8 & The pandemic is an effect of climate change & 4.76 & 1.01 & 743 & & 317 & \\
\hline r9 & Animals and plants live with coronaviruses & 4.93 & 1.54 & 715 & & 396 & \\
\hline $\mathrm{r} 10$ & The coronavirus made it possible to reduce emissions & 4.36 & 1.34 & 703 & & 380 & \\
\hline r11 & Confinement is coexisting with species & 4.16 & 1.55 & 762 & & 385 & \\
\hline r12 & Quarantine also affects species & 4.30 & 1.76 & 781 & & 394 & \\
\hline r13 & The vaccine is in nature & 4.19 & 1.80 & 764 & & 372 & \\
\hline r14 & Masks saturate the environment & 4.03 & 1.25 & 768 & & 367 & \\
\hline & Intentional & & & 783 & & & \\
\hline r15 & Ecologists would be relevant in this confinement & 4.17 & 1.54 & 767 & & & 360 \\
\hline r16 & Environmentalists would contribute in this quarantine & 4.15 & 1.61 & 770 & & & 386 \\
\hline r17 & Recyclers would help in this closure & 4.15 & 1.17 & 762 & & & 369 \\
\hline r18 & Savers would emerge in this health crisis & 4.10 & 1.82 & 751 & & & 375 \\
\hline r19 & Pedicabs would be essential in this pandemic & 4.03 & 1.51 & 751 & & & 395 \\
\hline r20 & Travidrive would be indispensable in this contingency & 4.07 & 1.63 & 703 & & & 394 \\
\hline r21 & Masks would contaminate in this epidemic & 4.11 & 1.50 & 732 & & & 393 \\
\hline
\end{tabular}

\section{Table 1. Descriptive of the instrument}

Note: Made with the study data. Method: Main axes, Rotation: Promax. Emotions (16\% of the total explained variance and alpha of, 780), Cognitive (12\% of the total explained variance and alpha of, 765), Intentions (7\% of the total explained variance and alpha of,
753). All items are answered with one of five options, ranging from $0=$ "not at all agree" to $5=$ "quite agree".

Establishing the exploratory factor structure of the three preponderant factors in relation to the 21 indicators, we proceeded to estimate the relationships between these three dimensions related to emotional, 
cognitive and intentional attitudes which explained $35 \%$ of the total variance (see Table 2).

\begin{tabular}{|c|c|c|c|c|c|c|c|c|}
\hline & 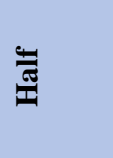 & 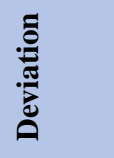 & 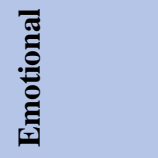 & نْ & 兽 & 폴 & 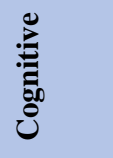 & - \\
\hline Emotional & 23.12 & 13.24 & 1,000 & & & 1,986 & 645 & 532 \\
\hline Cognitive & 22.35 & 15.46 & $325 *$ & 1,000 & & & 1,768 & 418 \\
\hline Intentional & 25.46 & 14.37 & $478 * * *$ & $541 * *$ & 1,000 & & & 1,689 \\
\hline
\end{tabular}

Table 2. Relationships between variables.

Note: Made with the data from the study; $* \mathrm{p}<, 01 ; * * \mathrm{p}<<, 001 ; * * * \mathrm{p}<, 0001$

The relationship structure weighs the inclusion of another factor that the literature identifies as dispositional ambivalence to account for those attitudes against and in favor of an object which may be the case of the pandemic. In other words, on the one hand, negative provisions are built in the face of the health and economic crisis, but also unusual work opportunities such as messaging are opened. In this way, the possible emergence of this fourth factor was observed, although adjusting the three factors would also be an option to increase the percentage of explained variance.

The adjustment and residual parameters $\lceil\chi 2=234.13(24 \mathrm{gl}) \mathrm{p}>, 05$; CFI $=$, 990; GFI =, 999; RMSEA $=$, 008 $\mathrm{J}$ suggest the non-rejection of the null hypothesis regarding the significant differences between the reflective trajectory structure subtracted from the literature with respect to the observed relationship structure.

\section{Discussion}

The contribution of the present work to the state of the question lies in the establishment of the reliability and validity of an instrument that measures attitudes towards the effects of the pandemic on the environment, suggesting the extension of the work towards contrasting the model in others. Scenarios.

In relation to the theory of attitudes, which highlight the three emotional, cognitive and intentional components, this work has shown the prevalence of this structure of reflective trajectories in a model, but the percentage of total variance suggests the inclusion of an ambivalent factor. Which would increase the predictive power of the model. In the virtual classroom the application of this finding in the didactic sequences will allow to establish dynamics oriented towards ambivalence; emotionality and reasoning about its effects on public resources and services.

As for the studies of attitudes which highlight the hegemony of the emotional component in the event of risk events, this work has shown that it is a multiple dimension in which indicators adjusted to anger, fear or anxiety converge in the face of the effects of pandemic in nature. These results will allow the design of pedagogical sequences related to education for sustainability, mainly regarding risk events.

Theoretical, conceptual and empirical frameworks seem to highlight the hegemony of cognitive dispositions to explain the emergence of attitudes to risk events such as a pandemic. In this sense, the present investigation has highlighted the factorial structure that explains the relationships between the affective, cognitive and intentional dimensions as a formative process of dispositions against or in favor of the effects of the coronavirus in nature.
However, regarding studies of attitudes towards the effects of the pandemic in the environment, which highlight the cognitive component, this work has shown that it explains a percentage of variance less than the affective dimension. This is so because the pandemic has been processed as a collateral problem to atmospheric and water pollution. Research lines related to these two dimensions in a health contingency situation will anticipate the effects of the pandemic on energy, gasoline or water users.

Regarding the products derived from the confinement of people; towels, masks, soap, water, alcohol or gel these could be objects of consumption and predictable from the cognitive dimension, but when the affective component prevails, they are processed as impositions rather than as preventive instruments. In other words, the effects of the pandemic on the environment seem to be related to fear, anger or anxiety rather than to processes of utility, benefit or gain.

In other words, affective attitudes prevail more than cognitive and intentional attitudes because the media and government health policy have focused their attention on the confidence of the governed rather than on their discipline or experience with epidemics. It is necessary to carry out studies that establish these communication differences between rulers and citizens in order to be able to observe the differences between attitudes of an affective order with respect to those of a cognitive or intentional order.

\section{Conclusion}

The contribution of the present work to the state of knowledge lies in the specification of a model for the study of attitudes towards pandemic effects in nature, although the research design limited the results to the work setting, suggesting the extension of this to a context of risk events.

In consultative terms, research provides the central elements for the construction of an environmental policy focused on the cognition of dispositions. It is about the design of pedagogical sequences oriented towards local sustainability in the management of municipal resources and services. In other words, from the construction of a public agenda it will be possible to discern between the deliberate, planned and systematic reasoning emerging from the pandemic, confinement and the health and economic crises.

\section{References}

1. Amemiya, M. (2020). Retrospective meta-analysis of the random and homogeneous effects of the validity of the risk perception scale. American Journal of Applied Scientific Research, 10 (4), 25-35

2. Anguiano, F. (2020). Meta-analysis of the effects of the entrepreneurship on local development: Implications for the 
COVID-19 coronavirus pandemic. International Journal of Research in Engineering \& Science, 8 (9), 40-47

3. Bustos, J. M. (2020). A review of findings about local development. Eureka, 17 (1), 141-161

4. Carreon, J. (2020). Reflective structure of voting intentions in favor of pandemic mitigation. American Journal of Applied Scientific Research, 6 (5), 1-7

5. Garcia, C. (2020). Specification a model for study of occupational health. Global Journal of Management \& Business Research, 1 (1), 1-6

6. Hernández, J. (2020). Specification of as social intervention model against COVID-19. Biomedical of Scientific \& technical Research, 26 83), 62-65

7. Limón, GA (2020). Specification of a model of need for information about COVID-19 coronavirus. International Journal of Social science Studies, 8 (6), 1-5
Molina, H. D. (2020). Peri-urban socio.environmental representations. Kulxulkab, 26 854), 5-12

9. Pérez, G. (2020). Attitudes toward the media spread of the COVID-19 coronavirus. International Journal of Humanities \& Social Science Invention, 9 (8), 20-25

10. Quiroz, C. Y. (2020). Exploratory factorial structure model of the perception of mobility bikeways. Proposal \& Representations, 8 (1), 1-14

11. Rivera, BL (2020). Exploratory structural algorithmic of perceived risk factor. International Journal of Humanities \& Social Science Invention, 10 (8), 26-30

12. Sandoval, F. R. (2020). Job expectations in the phase of risk events and collateral social effects. International Journal of Humanities Social Science and Education, 7 (5), 1-7

8.

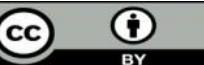

This work is licensed under Creative Commons Attribution 4.0 License

To Submit Your Article Click Here: Submit Article

DOI: $10.31579 / 2690-8808 / 013$
Ready to submit your research? Choose Auctores and benefit from:

* fast, convenient online submission

* rigorous peer review by experienced research in your field

* rapid publication on acceptance

* authors retain copyrights

* unique DOI for all articles

* immediate, unrestricted online access At

Auctores, research is always in progress.

Learn more www.auctoresonline.org/journals/journal-of-clinical-casereports-and-studies 